\title{
Intelligent Door Knocking Security System Using IOT
}

\author{
Dr. T. J.Nagalakshmia ${ }^{a}$ Nallavan. $G^{\text {b }}$, and Hari Prasath Sharma Sekaran ${ }^{\mathrm{c}}$ \\ a \\ Assistant professor, Department of ECE, Saveetha School of Engineering, Saveetha \\ Institute of Medical and Technical Sciences, Chennai. \\ ${ }^{\mathbf{b}}$ Assistant Professor, Department of Sports Technology, Tamilnadu Physical Education and Sports University, Chennai. \\ 'Research Scholar, Bharath University, Chennai-73
}

Article History: Received: 11 January 2021; Accepted: 27 February 2021; Published online: 5 April 2021

Abstract: In current day security is very important. Nowadays, in all places many robberies are going on. In this security issue, lock is the major parameter. The trustworthy on the lock should me made improve. The lock may be for main door lock, baggage lock, shutter lock, grill door lock, interconnecting door lock etc. This project is based on arduino board and IOT. And also this can be used for main door and for locker door. This lock works based on the knocking pattern. The owners knocking pattern is stored in the register. When the knocking pattern is detected by the sensor, it passes it to the arduino board microcontroller. Based on the trustworthiness of the pattern the lock works. This framework is easy for installation. It can be implemented for commercial use also.

Keywords: IOT, Arduino Uno board, Power supply, Bylynk App, DC motor, Motor driver circuit, Knock pattern, GSM module.

\section{Introduction}

The World has progressed significantly throughout the years and it has changed the manner in which we live, the manner in which we impart, the manner in which we learn and the manner in which we change. One of those extraordinary headways is progression in Technology. From creation of things like blades out of rocks to things like 3D printer to a super PC, Technology has made some amazing progress. This headway in Technology has been outstanding in the 21 st Century.

Be that as it may, with the points of interest and advantages, additionally came the disservices and difficulties. One of the instances of this headway can be taken as the creation of the IPhone. IPhone was a noteworthy redesign from the customary sort of utilizing a telephone since it was ready to call and content as well as had the capacity to play music, recordings, and download applications. Despite the fact that these were the favourable circumstances, there were numerous detriments like battery channel and the decline of vis-à-vis correspondence because of dependence on the cell phone. With such headways in innovation, there's dependably a requirement for security and protection.

One of the methods for verifying security is a mix of 'lock and key'. Present day locks and the locking framework are unquestionably increasingly intricate and regularly utilize a dabbed system on the key which give a more prominent security. In any case, the drawback is that it's the equivalent 'lock and key' system, which means, the key can generally be imitated with some exertion. One of the arrangements is to totally dispose of the 'lock and key' instrument itself. This venture plans to do likewise by setting up solid security basing on a 'Mystery thumping example', therefore the name, "Thump Based Security System". This framework is involved gadgets like Arduino, GSM Module, Servo Motor and so forth and utilizations a 'Mystery Knocking Pattern' which is known just to the proprietor of that specific safe, bag or some other Property or item that the gadget is introduced on. The expansion in security in executing this framework comes into the image in a few different ways.

\section{Existing Systems}

RFID technology can be used in the intelligent door knocking system. When anybody tries to open or knocks the door then this action will be sensed and sends information to the user via GSM. But anyone with the false RFID can open door. In finger print method, door will be opened when unique graphical security must be matched. If the culprit has the finger print then they can easily open the door.

In another method, the wireless LAN module fixed on the board receives the transmitted signal and transmits to the microcontroller. The microcontroller passes the data to the servo motor in order to complete the operations on the Door [1].

In thump impression technique, when we thump it, the arduino begins observing the primary thump to secondary thump and keeps the time gap period. In this work 6 thump impressions are taken. Therefore 5 timespans will come. These time lapses were converted interms of variables. Example, if the time period is less than $500 \mathrm{~ms}$, then 0 . If it is more than $500 \mathrm{~ms}$ then 1 . Like this the total 5 time lapses, converted into 5 digit password. These passwords are used to open the door lock. If it does not match, then lock will not be open.

\section{Proposed System}


If the entry way thump is entered correctly then the gate will be open. If the thump entry is wrong for consecutive three times then code will be locked and alert will transmitted to approved authenticated client.

\section{Working Principle}

In this project work, as an input device capacitive sensor is used. This sensor can detect the electrical capacitance of the human hand. This sensor is built by using aluminium foil, medium to high esteem resistor, wire and a capacitor. When touch sensor contacts with the finger the body capacitance is in parallel to the sensor's capacitance. This makes wavering recurrence decline. The microcontroller recognizes this property.

Here, 3 bits of aluminium foils are introduced on the external side of entry way. The clients can open the entry way by contacting these foils. Because of the usage of three foils, the detection of multifaceted of the finger is possible.

Here, the time period is characterized by RC. Where, $\mathrm{R}$ is the resistor, $\mathrm{C}$ is the capacitance of the foil. In this system we have to consider the capacitance experienced by the human finger. Suitable rearrangement can balance out sensor readings, making the entire framework solid.

Other than, microcontroller, voltage converter or comparator can be used. This framework can be further improved by using a touch cushion rather than aluminium foils. For example, if the independent momentary capacitive touch sensor used then it can send computerized flag specifically to microcontroller.

\section{BLOCK DIAGRAM \& DESCRIPTION}

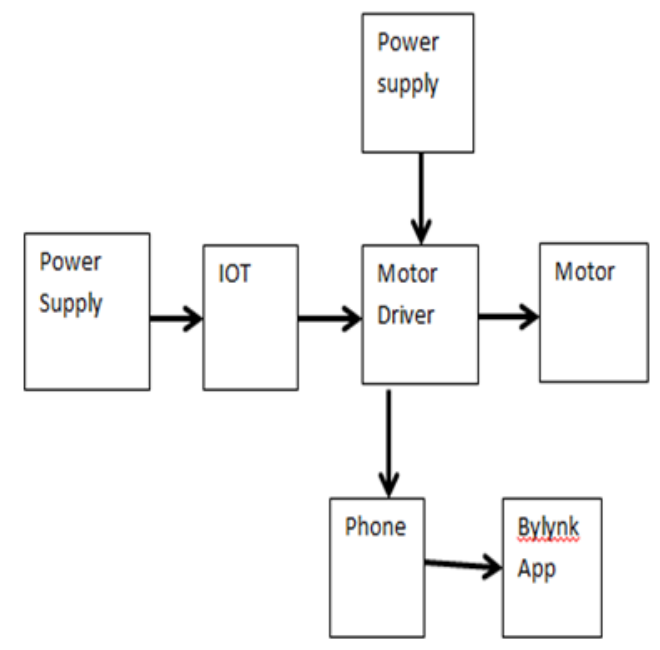

Fig. 1 Block Diagram of Intelligent Door Knocking System

In this work, the door lock is controlled by IOT and Bylynk app. The door is controlled by the motor driver. About the status of the door is delivered to the client mobile phone using bylynk app.

The description of the components are given below

\section{IOT (Internet of Things)}

It connects and exchanges the data with other devices and systems using internet. But the drawback is privacy and security. IOT can be used in consumer application field, commercial, industrial and infrastructure spaces. Recent technologies are developed in home automation systems, wearable technologies, in medical applications and remote monitoring systems.

\section{MOTOR DRIVE MODULE:}

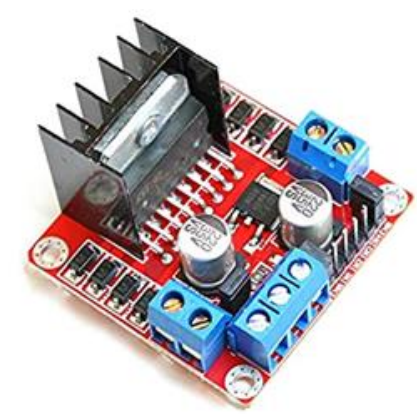

Fig 2 - L298N Motor Driver Module (Source: 2)

The L298N Motor Driver module consists of an L298 Motor Driver IC, 78M05 Voltage Regulator, resistors, capacitor, Power LED, 5V jumper in an integrated circuit.

When jumper is placed at that time only 78M05 voltage regulator is enabled. If the power supply is less than $12 \mathrm{~V}$, then the microprocessor is powered by voltage regulator. The speed control pin for Motor A is ENA and for 
Motor B is ENB. The direction control pins for Motor A are IN1 \& IN2 and for Motor B are IN3 \& IN4. This module cab used in robotics, in stepping motors and in drive DC motors. The motor driver used in the project is shown in the Fig.2.

\section{MOTOR}

DC motor is operated by direct current. It converts DC electrical energy into mechanical energy. This motor works on the principle of when a magnetic field and electric field interact then the mechanical force called as motoring action is produced. Fleming's left hand rule gives the direction of rotation.

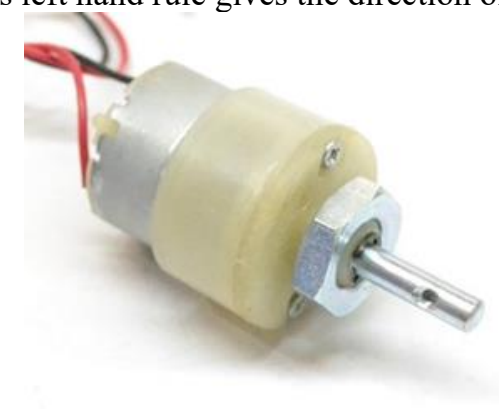

Fig. 3 - DC motor 60 RPM 12V

The Fig. 3 represents the DC motor used in the project. The metal gear which is used in it has better wear and tear properties. It requires no maintenance because; the gear box is sealed and lubricated with lithium grease. It runs smoothly from $4 \mathrm{~V}$ to $12 \mathrm{~V}$. It gives $60 \mathrm{RPM}$ at $12 \mathrm{~V}$.

\section{Tests and Results}

This home security system is having two stages. In first stage the client can fix where they want to mark the thump impression and successively they have to do the thump impression. In second stage, from the time gap between the thump impression code word is generated. If the code is correct then door will be unlocked. lock.

The proposed door locks security system shown in the Figure 4 . This system is attached on the door with the

When the client wants to open the door, the thumping data were collected. To detect the thumping, piezo electric based vibration sensors were used. These sensor collected data transferred to the arduino. If the data was an authenticated data, then flag will be set to open the door.

All activities are connected with the client's mobile. So the status of the door was continuously monitored by the client.

If suppose any unauthenticated person trying to open the door immediately alert will be given to the client mobile. This system is shown in the Fig. 5

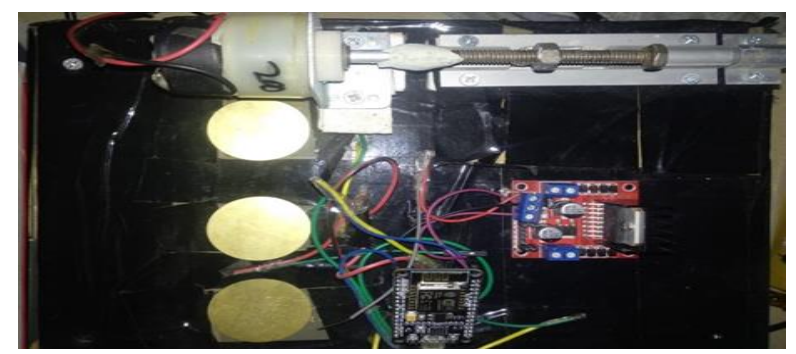

Fig. 4 Door lock security system

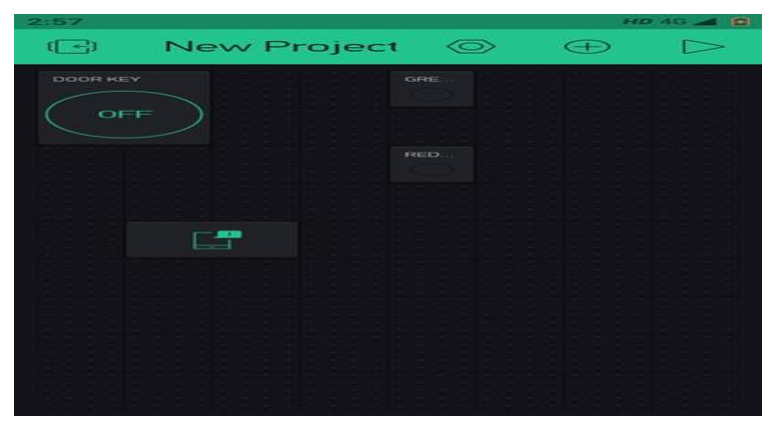

Fig 5: Mobile Alert using blynk app

\section{Pros and Cons}

The main drawback is if the door broken then no signal will be transmitted to the client. And the client not aware of this incident. And the advantage is, if any intruder trying to enter with wrong thumping, then alert will be sent to the client through their mobile phone. 
In future, the following feature can be added with this project.

If the person is authenticated person and the client having trust then the client can open the door remotely.

\section{Conclusion}

Thus the proposed framework is very simple and cheaper. The accuracy of the system is very high. So the client can control the entryway remotely. The bylynk app is also a free app. Based on the thumping on the door this security systems works. In future many advanced features like, remote monitoring and contolling of the door can be achieved.

\section{References}

1. SMART DOOR LOCKER SECURITY SYSTEM USING IOT”, Archana M, Gayathri G D,

Jayabharathi R, Jayasudha I, SSRG International journal of computer science and engineering,

Feb 2019

2. L298N motor driver module - Components 101.com

3. "Controlling and securing a Digital Home using Multiple Sensor Based Perception system Integrated with Mobile and Voice technology”, Avishek Ahmed, Tanvir Ahmed, Md.

SamawatUllah, Md. Manirul Islam, Research Gate, September 2011.

4. "Microcontroller based Home Security System with Remote Monitoring”, Nikhil Agarwal, International Conference on Electronic Design and Signal Processing (ICEDSP), Special Issue of International Journal of Computer Applications (0975 - 8887), 2012.

5. “A Review on Industrial Automation By Zigbee Based Wireless Remote Controller”, Minal Nikose, Pratibha Mishra, Avinash Agrawal, International journal of scientific \& technology research volume 3, Issue 4, April 2014

6. "Energy efficient Smart home based on Wireless Sensor Network using LabVIEW", JayashriBangali, Arvind Shaligram, American Journal of Engineering Research (AJER) (2013), eISSN : 2320-0847 p-ISSN : 2320-0936, Volume-02, Issue-12, pp-409-413.

7. "A Remote Home Security System Based on Wireless Sensor Network and GSM Technology", International conference on Networks Security, Wireless Communications and Trusted Computing (2010), ISBN: 978-0-7695-4011-5, Wuhan, Hubei.

8. "Sensor based home automation and security system”, M H Assaf, Ronald Mottoo, Sunil R Das. IEEE International Instrumentation and Measurement Technology Conference (I2MTC), 2012.

9. “ARDUINO Based industrial security system using piezo electric sensor”, R. Sai Charan Reddy, Vamsi Krishna, M.Krishna Chaitanya, M.Neeharika, K Prabhakara Rao. International Journal of Engineering and Techniques - Volume 4 Issue 1, Jan - Feb 2018.

10. “A New Approach to Smart Knock Detection Based Security System for Door Lock”, Amit Chaurasia, Umesh Kumar Dwivedi, Amita Chaurasia, Shubham Kumar Jain, International Conference on Intelligent Computing and Smart Communication 2019 pp 907-914.

11. "Digital Home: An All-in-one Device to Control most everything", Science news, Science Daily (Mar. 6, 2008).

12. "Construction of the home security system using the Internet technology", Takabayashi K., Fujita N., Nomura Y., Amada Y., Osaki T., Sugahara K., and Konishi R. 2002.. In Proceedings of the 41st SICE Annual Conference (August 05 - 07, 2002). SICE '02. IEEE Press, 461-465.

13. "Design and Implementation of Home Security Sytem based on WSNS and GSM Technology", I.Syam Krishna, J. Ravindra,. International Journal of Engineering Science and Technology” Volume 2, Special Issue 1, Page 139-142.

14. "Smart Home Security", K.K. Griffiths and R. Melanie, 2012, Homebuilding \& Renovating. Retrieved University of Leeds.

15. “Digital Health System in vehicles with Artificial Intelligence Configuration”, J.S.Nandhini,R. K. Jaiswal, P. Chaturvedi, R.Grover, International Journal of Emerging Technologies in Engineering Research (IJETER), Volume 6, Issue 10, October 2018. 